\title{
CATARACT EXTRACTION BY THE LATERAL ROUTE*
}

\author{
BY \\ KRISHNA SWAMI MEHRA \\ College of Medical Sciences, Benares, India \\ AND \\ R. B. L. GUPTA \\ Gandhi Eye Hospital, Aligarh, India
}

THE surgeon finds himself in difficulty when cataract extraction is planned in a patient who has had a fistulizing operation in the past. Then the cataract can be removed by making the incision in the lower half or by making a corneal incision. In cataract surgery difficulty is felt after operation in examining the condition and position of incision and stitches on the first post-operative dressing, and later on as well, because the patient does not open the eye completely and so the upper portion of the eyeball is not easily seen. There is a risk of hyphaema if the eye that has been operated upon is forcibly opened. Very often we are not able to observe any prolapse of iris which is being covered up by the upper lid. This prolapse is then noted on the tenth day when stitches are removed.

With this in mind Magdalena (1961) tried a lateral limbal incision in 22 cases of cataract extraction; fistulizing operations had been done in 3 of these cases in the past. He showed that with lateral limbal incision there is better post-operative supervision, less feeling of irritation, and a better view of the field of operation. He also showed that, in his series, direct astigmatism resulted after operation, which was better tolerated and had a tendency to disappear.

We were impressed by Magdalena's observation and so thought of trying this lateral route for taking out cataractous lenses.

\section{Methods and Materials}

This technique of lateral-route extraction was tried in 48 patients-29 males and 19 females. The ages in this series ranged from 55 to 70 years. All the cases except two had senile mature or immature cataract; in 2 patients a draining bleb at the 12 o'clock meridian was present.

As far as the pre-operative preparation and local anaesthesia were concerned it was the same as that normally used-Anethaine 1 per cent. locally as drops and 4 per cent. Novocaine for infiltration anaesthesia. Lids were retracted by two stitches in the upper lid and one stitch in the lower lid. A superior rectus stitch was used and a stitch was also passed in between the lateral rectus muscle and sclera just near the attachment of the muscle. A conjunctival flap $2 \mathrm{~mm}$. broad was made from 6 o'clock to 12 o'clock in the temporal 
half. A conjunctivo-episcleral limbal silk stitch was applied at the 9 o'clock meridian in the right eye and at the 3 o'clock meridian in the left eye. A limbal incision with a keratome was made at 3 o'clock in the left eye and at 9 o'clock in the right eye. This incision was enlarged, extending from 6 o'clock to 12 o'clock in the lateral half. A peripheral iridectomy or broad iridectomy, as the case required, was done at the 10.30 meridian in the right eye and 1.30 meridian in the left eye. Intracapsular lens extraction either with forceps or erisophake was done. The stitch was tied. Two conjunctival stitches were given in the upper and lower outer quadrants. Sterile air was injected into the anterior chamber. Six weeks after the operation patients were refracted for glasses.

\section{Observations}

On every operation day a few cases of cataract were operated upon by the lateral route, the others by the superior route. In the post-operative follow-up these observations were made:

(1) Patients operated on by the lateral route complained of less irritation compared with those operated on by the superior route.

(2) The operative field position of flap and stitches was more easily seen, and seen in detail as well in patients operated on by the lateral route.

(3) Six weeks after discharge refraction of the operated eye was done. It was observed that out of these 48 patients only 10 accepted cylindrical lenses of $+1 \cdot 25$ to $+2.0 \mathrm{D}$. in axis ranging from 60 to $90^{\circ}$ in the right eye and 90 to $135^{\circ}$ in the left eye; 22 accepted cylinders ranging from +0.5 to $+1 \cdot 0 \mathrm{D}$.; 16 did not accept any cylinder.

(4) The scar in the lateral half of the limbus did not give any bad cosmetic effect nor did it affect the field of vision.

\section{Summary}

In 48 patients with senile cataract, lens extraction was carried out by a lateral incision instead of a superior one. It was observed that with this route there is better post-operative supervision and the astigmatism which results is less than is seen with a superior incision.

I am grateful to Dr. K. N. Udupa, Principal, College of Medical Sciences, for permitting me to undertake this work.

\section{REFERENCE}

Magdalena, J. (1961). Arch. Soc. oftal. hisp.-amer., 21, 398. 